\title{
Unrevealing model compounds of soil conditioners impacts on the wheat straw autohydrolysis efficiency and enzymatic hydrolysis
}

\author{
Xinxing Wu ${ }^{1,2}$, Wei Tang ${ }^{1,2}$, Chen Huang ${ }^{1,2}$, Caoxing Huang ${ }^{1,2}$, Chenhuan Lai ${ }^{1,2}$ and Qiang Yong ${ }^{1,2^{*}}$
}

\begin{abstract}
Background: Soil-derived exogenous ash (EA) poses a challenge toward lignocellulosic autohydrolysis due to its buffering capacity. Previous works focusing on this phenomenon have failed to also investigate the role that soluble salts, and organic matter plays in this system. Herein, sodium phosphate and sodium humate were employed as model buffering compounds representing soluble salts and organic matter and dosed into a de-ashed wheat straw (DWS) autohydrolysis process to show the potential impacts of WS attached soil conditioners on the WS autohydrolysis efficiency which would further affect the enzymatic digestibility of autohydrolyzed WS.

Results: Results showed that with the increasing loadings of sodium phosphate and sodium humate resulted in elevated pH values (from 4.0 to 5.1 and from 4.1 to 4.7, respectively). Meanwhile, the reductions of xylan removal yields from $\sim 84.3-61.4 \%$ to $72.3-53.0 \%$ by loading (1-30 g/L) sodium phosphate and sodium humate during WS autohydrolysis lead to a significant decrease of cellulose accessibilities which finally lead to a reduction of the enzymatic digestibility of autohydrolyzed WS from $75.4-77.2 \%$ to $47.3-57.7 \%$.
\end{abstract}

Conclusion: The existence of different types soil conditioner model compounds results in various component fractions from autohydrolyzed WS in the process of autohydrolysis. A lack of sufficient xylan removal was found to drive the significant decrease in enzymatic accessibility. The results demonstrated the various effects of two typical tested soil conditioners on WS autohydrolysis and enzymatic hydrolysis.

Keywords: Autohydrolysis, Phosphate, Humate, Enzymatic hydrolysis, Enzymatic accessibility

\section{Background}

With the developments of modern agriculture, approximately 200 billion tons of agricultural residues are now generated annually across the world [1]. Effective utilization of such huge quantities of lignocellulosic materials has become a key goal for societies that find themselves

\footnotetext{
*Correspondence: swhx@njfu.com.cn

${ }^{1}$ Key Laboratory of Forestry Genetics \& Biotechnology (Nanjing Forestry University), Ministry of Education, Nanjing 210037, People's Republic of China

Full list of author information is available at the end of the article
}

with such an overabundance [2]. One promising avenue for these materials was to use them as feedstock for producing bioethanol, amongst other chemicals. Doing so could both reduce greenhouse gases emissions and promote carbon balance in ecosystem [3-5]. Due to its abundant benefits, many researchers attempted to advance the utilization of lignocellulose or lignocellulose-based products [6-8]. One particularly abundant agricultural residue is wheat straw, which is considered an interesting feedstock for biorefining due to its high carbohydrate content $(\sim 28-39 \mathrm{wt} \%$ cellulose and $\sim 23-24 \mathrm{wt} \%$ hemicellulose). However, efficient utilization of wheat straw to

c) The Author(s) 2020. This article is licensed under a Creative Commons Attribution 4.0 International License, which permits use, sharing, adaptation, distribution and reproduction in any medium or format, as long as you give appropriate credit to the original author(s) and the source, provide a link to the Creative Commons licence, and indicate if changes were made. The images or other third party material in this article are included in the article's Creative Commons licence, unless indicated otherwise in a credit line to the material. If material is not included in the article's Creative Commons licence and your intended use is not permitted by statutory regulation or exceeds the permitted use, you will need to obtain permission directly from the copyright holder. To view a copy of this licence, visit http://creativeco mmons.org/licenses/by/4.0/. The Creative Commons Public Domain Dedication waiver (http://creativecommons.org/publicdomain/ zero/1.0/) applies to the data made available in this article, unless otherwise stated in a credit line to the data. 
generate valuable products requires a both efficient and affordable pretreatment stage in order for subsequent enzymatic hydrolysis to render acceptable quantities of upgradable monosaccharides [9].

To date, an extensive breadth of pretreatment methods have been developed to disrupt the solid matrix comprising lignocellulosic biomasses [10-13]. Autohydrolysis, which employs water as the only media, remains a potential prospect for industrial application due to its simplicity, low cost, and efficiency. It has also been reported to pair well with standard cellulolytic hydrolysis unit operations [14]. Over the course of autohydrolysis pretreatment, significant amounts of hemicellulose plus a minor amount of lignin are degraded and rendered soluble in the aqueous media. To achieve this effect, autoionized water at high temperatures leads to abscission of hemicellulosic acetyl groups which render the aqueous medium mildly acidic ( $\mathrm{pH} 3-4)$. However, this causes autohydrolysis to be a pH-dependent pretreatment. Therefore, fluctuations to pretreatment efficiency tend to be highly related to the raw material properties, including hemicellulosic acetyl content and exogenic ash ("EA").

Imprecise harvesting and handling of agricultural residues inevitably results in the inclusion of farmland soil within feedstock. The EA content in biomass after harvesting could exceed $20 \mathrm{wt} \%$ of the dry weight of biomass by multi-pass operations [15]. Previously, some research has noted that excessive ash found in agriculture residues results in the autohydrolysis medium exhibiting strong buffer capacity and therefore low autohydrolysis efficiency which could finally lead to reductions of enzymatic hydrolysis efficiency. Due to this effect, a waterwashing stage is often applied to reduce the ash content of agricultural residues in order to achieve the desired level of autohydrolysis efficiency [16]. The mechanism for this buffering was recently found to be cation exchange reactions caused by insoluble minerals (ash) present in the soil [17]. However, the buffering caused by two other key fractions of EA, soluble salts and organic matter, are overlooked due to their relatively minor quantities and the amounts of the two residual components in EA would be enhanced by fertilization of soil.

Growth and proliferation of agricultural crops tends to be highly dependent upon the presence of phosphorus provided by fertilizers widely used in cultivation of agricultural crops [18]. The utilization of phosphate fertilizers could accelerate the growth of crop roots, promote the absorption of water and nutrients by crops, improve the water use efficiency of crops and the ability to absorb short-term drought during water shortage [19]. Besides, phosphate, as the main component of phosphate fertilizers, has the ability to combine with metal cations in soil to increase the soil buffering capacity, which can behave as a $\mathrm{pH}$ buffering compound when found in aqueous media [20]. This is particularly problematic for autohydrolysis, as over $2.5 \mathrm{wt} \%$ phosphorus existed in ash derived from corn stover [21]. The remaining phosphorus would be released in the form of phosphate which could further influence lignocellulosic autohydrolysis. However, apart from phosphorus-providing fertilizers, around $2.0-2.8 \mathrm{wt} \%$ organic matters normally existed in a fertile soil to increase the soil stability and humic acids also comprise a large fraction of the organic matter present in farmland soil [22]. Humic acid could also be used as soil conditioner because it could enhance the fertilizer efficiency, improve the quality of soil and so on [23]. The high levels of phenolate and carboxylate functional groups existed in humic acid and its negative surface charges contribute to its high ability to bind metal cations [24]. Humic acids also could be protonated due to its polyelectrolyte effect and heterogeneity. Therefore, using humic acid as soil conditioners normally combined with conventional fertilizers could exert strong buffering capacity through the mechanisms of metal cations liberations by resisting the $\mathrm{pH}$ change of the soil [25]. Meanwhile, humic acid also displays surfactant-like behavior because of its specific chemical structures. Non-cationic surfactants present during autohydrolysis pretreatment could capture some of the lignin released into the liquid phase by forming emulsions which finally resulted in more lignin removal from lignocellulose [26]. It could be hypothesized that the content of humic acid in soil exerts two possible effects upon autohydrolysis performance (1) buffering capacity, or (2) enhancing delignification of pretreated residue. Therefore, considering the better contributions to the soil buffering capacity of these two soil conditioners (sodium phosphate and sodium humate),

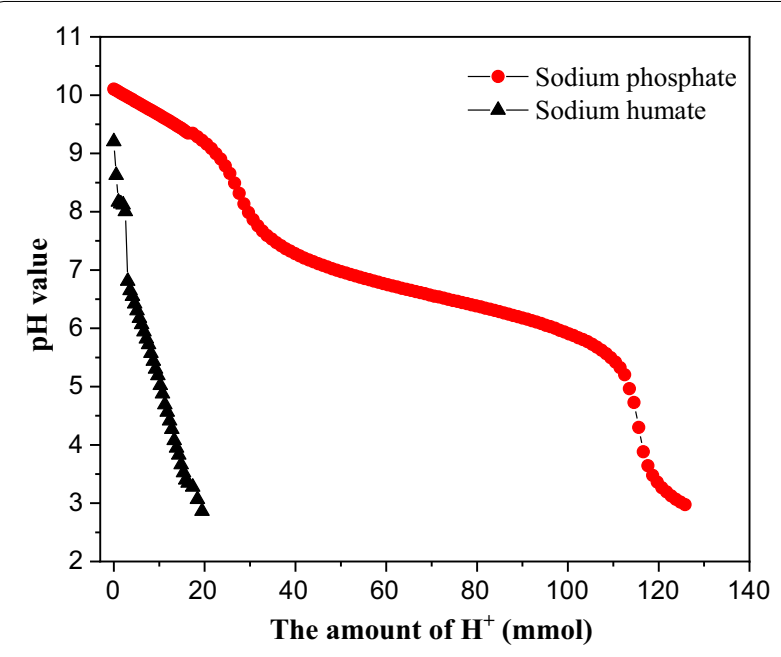

Fig. 1 Acid titration curve of buffering model compounds (10 g/L) 


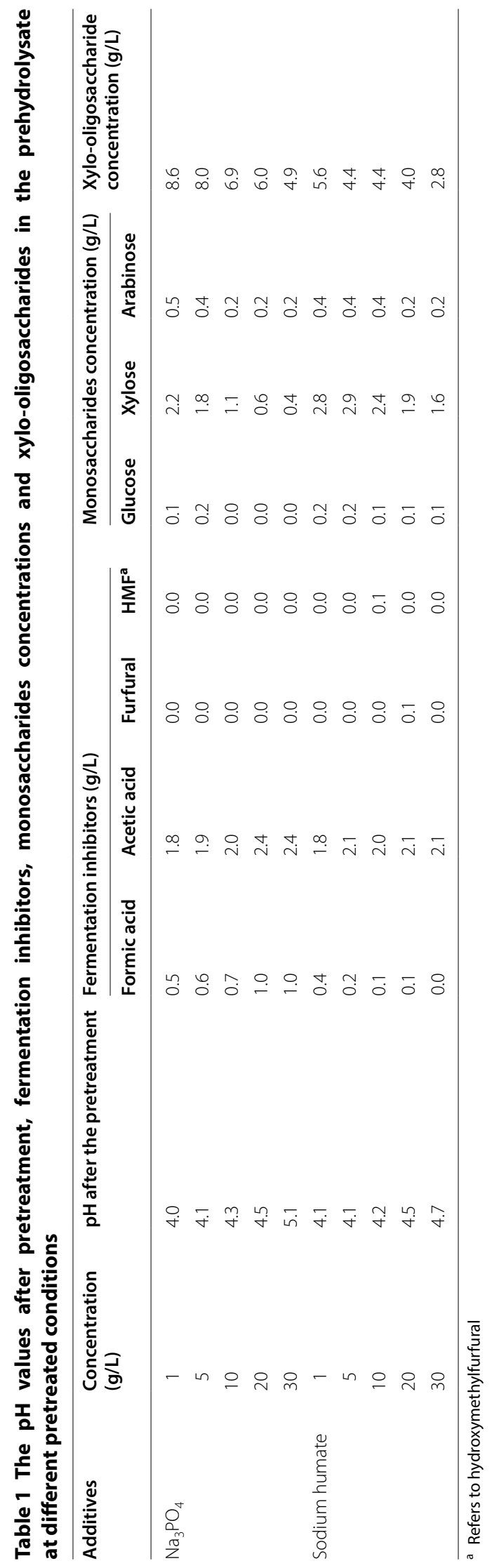


we studied the effects of sodium phosphate and sodium humate as model compounds of soil conditioners to better grapple with the effects that EA-derived soluble salt and organic matter exert upon autohydrolysis efficiency.

\section{Results and discussion}

Roles of buffering components on autohydrolysate properties

Autohydrolysis of biomass has fostered considerable interests due to its weak acid medium without any other chemicals additions that can be imposed [27]. Normally, through autohydrolysis, xylan and lignin were fractionated which lead to an increase of cellulosic surface exposed to the cellulase. However, if buffering compounds existed in the process of lignocellulose autohydrolysis, the pretreatment efficiency might be restricted because of the reduction the $\mathrm{H}^{+}$in the liquid. Based on the dilute acid titration results in Fig. 1, sodium phosphate exerted a much higher buffering capacity than sodium humate. When decreasing the $\mathrm{pH}$ from 6.5 to 3 , sodium phosphate consumed $356.0 \mathrm{mmol}$ $\mathrm{H}^{+}$while sodium humate only consumed $19.4 \mathrm{mmol} \mathrm{H}^{+}$ at the same concentration $(10 \mathrm{~g} / \mathrm{L})$. Therefore, it can be imagined that the same loadings of two different buffering compounds could result in various effects on the pretreatment efficiency. As shown in Table 1, increasing dosages (from 1 to $30 \mathrm{~g} / \mathrm{L}$ ) of sodium phosphate and sodium humate in WS autohydrolysis resulted in an increase to prehydrolysate $\mathrm{pH}$ values from 4.0 to 5.1 and from 4.1 to 4.7, respectively. According to our previous report, the $\mathrm{pH}$ of prehydrolysate generated without the presence of buffering compounds was 3.8 under the same pretreatment parameters [28]. Obviously, the added buffering compounds lead to a reduction to $\left[\mathrm{H}^{+}\right]$in the cooking medium. Importantly, we previously asserted that the acidity of the cooking results in different extents of lignocellulosic degradation by the pretreatment. But from the results regarding chemical composition of the prehydrolysate (Table 1), no changes to acetic acid concentrations in the prehydrolysate were detected regardless of the addition of buffering compounds. The extent of deacetylation during lignocellulose autohydrolysis was tightly related to the pretreatment parameters (temperature and cooking time) [29]. In this work, the autohydrolysis parameters were maintained at same level. Furthermore, similar results were also observed in another report in the literature [30].

Meanwhile, we also found that no HMF and furfural were detected in the prehydrolysate in the presence of the buffering components. This is not surprising, given that their generation is dependent upon acid-catalyzed dehydration of monosaccharides. Furthermore, these monosaccharides can only be formed from acid hydrolysis of hemicellulosic oligosaccharides [31, 32]. Therefore, a lessened extent of acidity results in lesser formation of all these components. Specifically, increasing loadings (from 1 to $30 \mathrm{~g} / \mathrm{L}$ ) of sodium phosphate and sodium humate caused the concentrations of xylose to be decreased from 2.2 to $0.4 \mathrm{~g} / \mathrm{L}$ and from 2.8 to $1.6 \mathrm{~g} / \mathrm{L}$, respectively. It was also observed that the xylo-oligosaccharide concentrations also decreased from 8.6 to $4.9 \mathrm{~g} / \mathrm{L}$ and from 5.6 to $2.8 \mathrm{~g} / \mathrm{L}$, respectively. To further understand the effects of the buffering by phosphate and humate, additional properties of prehydrolysate were analyzed in addition to the chemical composition of pretreated residues.

\section{Effects of additional buffering compounds in WS autohydorlysis on the prehydrolysate physical characterization and the chemical composition of pretreated WS}

A significant amount of xylan (up to $80 \mathrm{wt} \%$ ) could be removed from WS under the tested pretreatment conditions $\left(180^{\circ} \mathrm{C}, 40 \mathrm{~min}\right)$. However, we have already shown from the results in Table 1 that things change when the tested buffering compounds are added during autohydrolysis. From Table 2, the percentage of xylan removal deceased from 84.3 to $61.4 \%$ and from 72.3 to $53.0 \%$ with increasing dosages of sodium phosphate and sodium humate (from 1 to $30 \mathrm{~g} / \mathrm{L}$; respectively). These results matched the minor concentrations of degradation products in the prehydrolysate we observed. In general, the amount of $\mathrm{H}^{+}$in similar solvent conditions is clearly the key index for autohydrolysis performance. However, the properties of the cooking liquor might be changed by the loadings of buffering compounds.

The activities of hydronium ions $\left(\mathrm{H}^{+}\right)$in liquid are normally enhanced when the solution has high ionic strength, a parameter that can be measured through electric conductivity. As shown in Fig. 2A, the electric conductivities of the sodium phosphate-containing autohydrolysate increased from 0.8 to $3.1 \mathrm{~S} / \mathrm{m}$. Only minor changes of electric conductivities (ranging from 0.3 to $0.1 \mathrm{~S} / \mathrm{m}$ ) were found for the sodium humate autohydrolysate. This difference could be explained by the fact that humic acid as a polyelectrolyte is fundamentally different from the salt (sodium phosphate) which are comparing it against. Specifically, it is possible that the sodium humate could absorb $\mathrm{H}^{+}$in the liquid based on its incomplete dissociation properties. Therefore, the activity of $\mathrm{H}^{+}$in the prehydrolysate of sodium humate might be lower than that of sodium phosphate due to its low ionic strength and minimal contribution to solution conductivity [33].

As shown in Table 2, enhanced delignification (ranging from 18.6 to $43.7 \%$ ) was achieved by additions of sodium humate, however no significant change to delignification (ranging from 18.1 to $23.3 \%$ ) was observed for sodium 
Table 2 Effects of buffering compounds on the chemical compositions of pretreated WS

\begin{tabular}{|c|c|c|c|c|c|}
\hline \multirow[t]{2}{*}{ Additives } & \multirow[t]{2}{*}{$\begin{array}{l}\text { Concentration } \\
\text { (g/L) }\end{array}$} & \multicolumn{2}{|c|}{$\begin{array}{l}\text { Recovery yield } \\
(\%)\end{array}$} & \multicolumn{2}{|c|}{$\begin{array}{l}\text { Removal yield } \\
\text { (\%) }\end{array}$} \\
\hline & & Solid & Glucan & Xylan & Lignin \\
\hline \multirow[t]{5}{*}{$\mathrm{Na}_{3} \mathrm{PO}_{4}$} & 1 & 59.6 & 87.6 & 84.3 & 20.2 \\
\hline & 5 & 61.4 & 89.1 & 83.5 & 22.0 \\
\hline & 10 & 61.2 & 90.5 & 80.4 & 23.3 \\
\hline & 20 & 61.9 & 92.2 & 70.6 & 19.9 \\
\hline & 30 & 70.9 & 94.3 & 61.4 & 18.1 \\
\hline \multirow[t]{5}{*}{ Sodium humate } & 1 & 58.8 & 88.6 & 72.3 & 18.6 \\
\hline & 5 & 59.4 & 85.5 & 70.9 & 31.7 \\
\hline & 10 & 59.6 & 86.4 & 69.1 & 43.7 \\
\hline & 20 & 61.2 & 87.2 & 64.5 & 41.8 \\
\hline & 30 & 61.6 & 89.8 & 53.0 & 38.1 \\
\hline
\end{tabular}

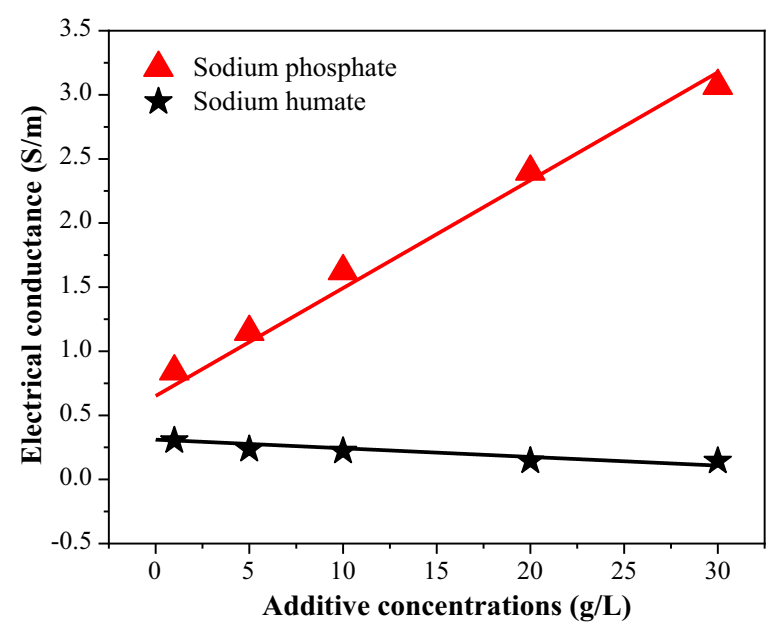

Fig. 2 Electric conductivity of the prehydrolysate after pretreatment

phosphate. It has been reported that lignin removal from lignocellulose in autohydrolysis is tightly correlated to elevated temperatures [34]. Previous researches have pointed that parts of lignin melt at high temperature and further degrade to other products which eventually are solubilized into prehydrolysate. Humic acid itself was considered as a natural organic surfactant (contains aromatic rings) and its chemical structure can be quite similar with lignin [35]. Researchers have mentioned that humic acid could be used as the substitutes for conventional surfactants in some applications [36]. Therefore, it can be imagined the melted lignin from lignocellulose during autohydrolysis might be further extracted by the sodium humate acting as a surfactant in the system.

Finally, we observed similar levels of glucan recovery (above $85 \mathrm{wt} \%$ ) despite variance in xylan removal and

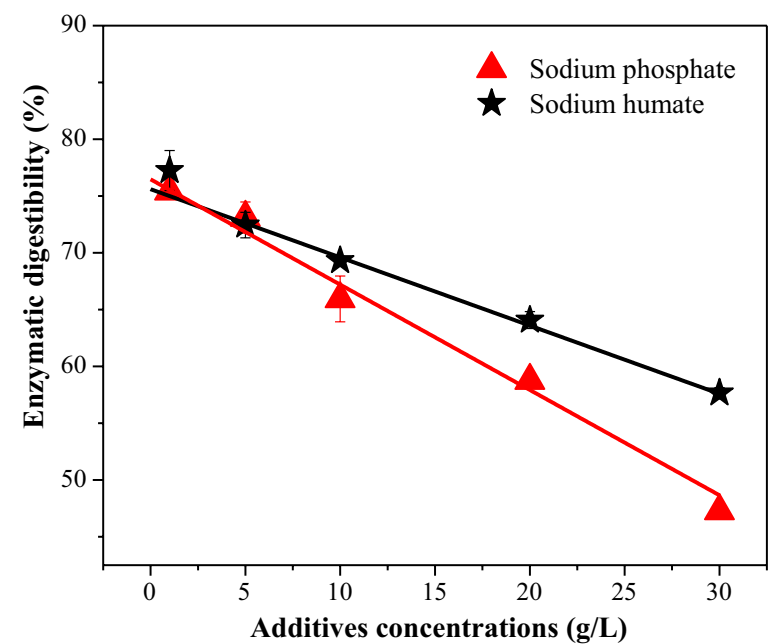

Fig. 3 Effects of buffering compounds added in wheat straw autohydrolysis on the 72-h enzymatic digestibility of pretreated residue

delignification. This observation was attributed to the chemical stability of cellulose at the autohydrolysis conditions tested [37]. However, we do expect that enzymatic digestibility will be changed based on the already discussed differences in removal of xylan and lignin.

Effects of loading buffering compounds on the enzymatic digestibility of pretreated WS

Enzymatic hydrolysis results were no doubt the key rings which could be used to evaluate one pretreatment efficiency [38]. Figure 3 displays the effects of buffering compounds on the 72-h enzymatic digestibility of the pretreated residues. As shown in Fig. 3, with the increasing dosages (from 1 to $30 \mathrm{~g} / \mathrm{L}$ ) of sodium phosphate and sodium humate, the enzymatic digestibility of pretreated residues decreased from 75.4 to $47.3 \%$ and from 77.3 to $57.7 \%$, respectively. Interestingly, linear relationships of $y=76.5-0.9 \mathrm{x}$ and $y=75.4-0.6 \mathrm{x}$ were recorded between the added amounts of sodium phosphate and sodium humate with the enzymatic digestibility of pretreated residues, respectively. Previous results indicated the increasing loadings of EA in WS autohydrolysis could result in a decrease to xylan removal of pretreated residues, which penalized downstream enzymatic digestibility [28]. Residual xylan in pretreated residues has been described to exert a "blocking effect" upon the substrate's surface, which renders unsuccessful enzymatic digestion [39]. To negate or eliminate the unwanted buffering effects caused by ash during autohydrolysis, strategies of de-washing and addition of sulfuric acid and exchangeable metal salts have been successfully applied in previous 
work [21, 40, 41]. Previous studies have also observed that the removal of organic matter alone from the soluble mixtures of EA can lead to an increasing enzymatic digestibility of autohydrolyzed WS with EA components [28]. If part of sodium phosphate is replaced by sodium humate of the same quality and applied to WS autohydrolysis, the enhancement for enzymatic digestibility of autohydrolyzed WS will be reduced due to the reductions of buffering effects and certain amounts of delignification during autohydrolysis process, compared to pretreatment with sodium phosphate alone. However, even all the $30 \mathrm{~g} / \mathrm{L}$ sodium phosphate was replaced by sodium humate, the 72-h enzymatic digestibility of autohydrolyzed WS was only $57.7 \%$. Therefore, it could be speculated the WS autohydrolysis efficiency would be also hugely restricted by the co-existence of sodium phosphate and sodium humate. For autohydrolysis, significant amounts of xylan removal from lignocellulose exposes more accessible area of pretreated residues for enzymatic attack [42]. It was also reported that in the pretreatment of corn stover, the extent of xylan removal is more critical for establishing strong enzymatic digestibility compared to delignification [43]. According to the extent of xylan removal, it seemed the enzymatic digestibility of pretreated residues with $30 \mathrm{~g} / \mathrm{L}$ sodium humate addition in pretreatment should be lower than that of $30 \mathrm{~g} / \mathrm{L}$ sodium phosphate addition. However, the truth was opposite. In general, we also found that relatively higher amounts of lignin were removed in the presence of sodium humate versus sodium phosphate humate. It is widely agreed upon that lignin removal is also beneficial towards cellulolytic hydrolysis of pretreated lignocellulose by reducing non-productive adsorption between enzyme and residual lignin $[44,45]$. Therefore, despite the dosages of sodium humate create a huge obstacle for xylan removal from lignocellulose, attributing its effects on lignin removal, the morphological properties of pretreated WS might be changed which finally resulted in higher enzymatic digestibility of pretreated WS than that of sodium phosphate [46]. To better explain the changes of pretreated residues enzymatic digestibility, the enzymatic accessibility was estimated using a dye adsorption assay.

\section{The relationship between cellulase accessibility and enzymatic digestibility of pretreated WS}

Dye adsorption test has been successfully applied to estimate the enzymatic accessibility of pretreated residues. Furthermore, its results have been shown to correlate well with enzymatic hydrolysis outcome [47]. As shown in Fig. 4, an increase of enzymatic accessibility of pretreated residues could lead to an increase in enzymatic digestibility. As we previously pointed out, the

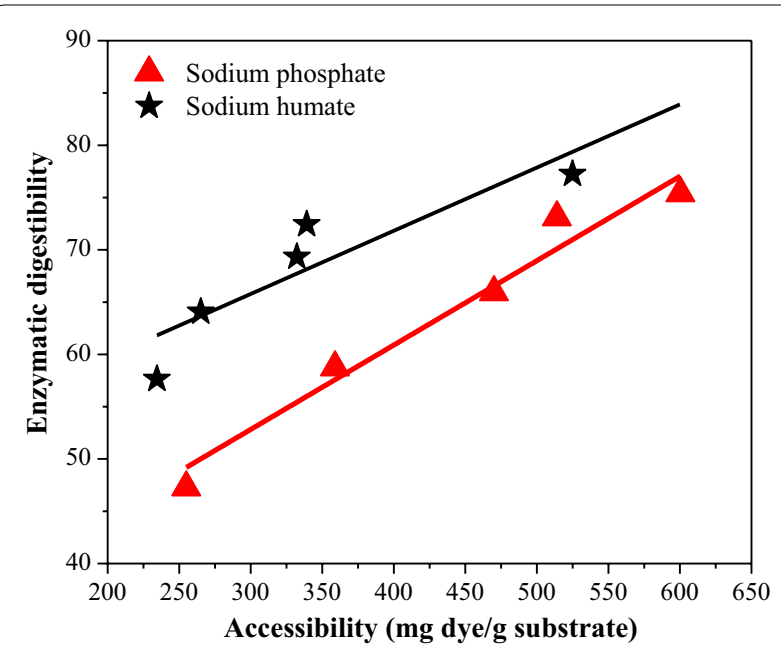

Fig. 4 Relationships between enzymatic accessibility and digestibility of pretreated residues

unwanted buffering effects caused by EA in WS autohydrolysis lead to the decreasing enzymatic accessibility digestibility [28]. Similar trends were also observed while model buffering compounds of soil conditioners were dosed into WS autohydrolysis. Obviously, attributing to the model buffering compounds involved in WS autohydrolysis, the lesser extent of xylan removal is partially to blame for the decline in enzymatic accessibility for the pretreated residue. As shown in Fig. 4, increasing dosages (from 1 to $30 \mathrm{~g} / \mathrm{L}$ ) of sodium phosphate and sodium humate resulted in accessibilities decreasing from 600.4 to $255.0 \mathrm{mg}$ dye/g substrate and from 525.0 to $234.5 \mathrm{mg}$ dye/g substrate, respectively. The dosage response is most likely due to their strong buffering capacities. Despite the possibility of sodium humate increasing delignification, these results showed that its self-buffering capacity provided more of a negative influence upon digestibility compared to the possible benefit of improved delignification. The results summarized the different extent changes of pretreated WS accessibility which were mainly attributed to the existence of various buffering compounds in WS autohydrolysis and the accessibility was highly related to the efficiency of enzymatic digestibility.

\section{Conclusion}

Autohydrolysis efficiency was found to be significantly reduced by the loadings of buffering compounds. The two compounds provided model systems that were found to prevent $\left[\mathrm{H}^{+}\right]$from reaching the desired levels, leading to a decrease in xylan removal. This was consistent across both sodium humate and sodium phosphate. Furthermore, the decrease in xylan removal also translated to low enzymatic digestibility. This was largely an issue 
of substrate accessibility, as revealed by a dye adsorption assay. Interestingly, improvement of delignification by loading sodium humate did not translate to any improvement in digestibility given the buffering effects of sodium humate. Therefore, our results show that two model compounds of soil conditioner that is often included in lignocellulosic crop residues also could buffer autohydrolysis media. These findings should guide future work looking to curb this buffering effect.

\section{Methods}

\section{Materials and reagents}

Wheat straw (WS) was obtained from a local farmer in Shandong province, China. Raw WS was treated by the reported procedures in our previous work to remove selfattached EA [28].

Sodium humate derived from lignite was purchased from Aladdin Reagent (Shanghai, China). The cellulase (Cellic ${ }^{\circledR}$ CTec2) used in this work was purchased from Novozymes (NA, Franklinton, USA) with a measured filter paper activity of $250.0 \mathrm{FPU} / \mathrm{mL}$. All remaining solvents, chemicals and reagents were of at least analytical grade.

\section{Autohydrolysis of WS}

Autohydrolysis pretreatment was performed in a laboratory-customized oil bath reactor. Prior to pretreatment, the $\mathrm{pH}$ of the formulated phosphate and sodium humate solutions was reduced to $\mathrm{pH} 6.5$ through addition of concentrated hydrochloric acid, respectively. For pretreatment, the reactor was loaded with $50 \mathrm{~g}$ (based on dry weight) of WS. In addition, varying concentrations $(\sim 1-30 \mathrm{~g} / \mathrm{L})$ of either phosphate or sodium humate solutions were loaded at solid to liquid ratio $1: 10(\mathrm{w} / \mathrm{v})$. The vessel temperature was raised from 60 to $180{ }^{\circ} \mathrm{C}$ at a heating rate of $2{ }^{\circ} \mathrm{C} / \mathrm{min}$, and then held at the maximum temperature for $40 \mathrm{~min}$. Pretreatment parameters were selected based on available literature $[16,29]$. When pretreatment was completed, the reactor was immediately transferred from the oil bath to an ice water bath. After cooling down the reactor to room temperature, cloth bags were used to separate pretreated residues from liquid prehydrolysate. Finally, the pretreated solid residues were washed using distilled water until the wash water was neutral, and the pretreated residues were stored in sealed plastic bags at $4{ }^{\circ} \mathrm{C}$ for $48 \mathrm{~h}$ to equilibrate moisture.

\section{Dilute acid titration of additional buffering compounds}

$0.5 \mathrm{~g}$ sodium phosphate or sodium humate was dissolved with $50 \mathrm{~mL}$ de-ionized water with a stirring bar at the speed of $180 \mathrm{rpm}, 50{ }^{\circ} \mathrm{C}$ for $1 \mathrm{~h}$, respectively. After mixing well, $0.1 \mathrm{M} \mathrm{H}_{2} \mathrm{SO}_{4}$ was applied to titrate the mixture at a speed of $0.5 \mathrm{~mL} / \mathrm{min}$ that was actively being agitated at $150 \mathrm{rpm}$. A multi-water quality meter (MM-60R, TOADKK, Tokyo, Japan) equipped with glass composite electrodes was used to record $\mathrm{pH}$ change. The terminal $\mathrm{pH}$ value was set at 3.0 and the $\mathrm{pH}$ value in the liquid of testing sample was automatically recorded every $30 \mathrm{~s}$.

\section{Electric conductivity determinations of the WS autohydrolysate}

To measure the electric conductivity of the prehydrolysate, $30 \mathrm{~mL}$ prehydrolysate was centrifuged at $8000 \mathrm{rpm}$ for $10 \mathrm{~min}$ and then the supernatant was poured into a clean $50-\mathrm{mL}$ beaker. Next, a conductivity meter was lowered into the solution. Then stable results were recorded.

\section{Enzymatic hydrolysis of autohydrolysis-pretreated WS}

Enzymatic hydrolysis was performed in 125-mL screwcapped glass bottles. Hydrolysis was conducted at a substrate loading of $5 \%(\mathrm{w} / \mathrm{v})$ of pretreated residues in a $50 \mathrm{mM}$ citric acid buffer $(\mathrm{pH}=4.8)$ with an enzyme dosing of $25 \mathrm{FPU} / \mathrm{g}$-glucan. $0.2 \mathrm{~mL}$ of $10 \mathrm{~g} / \mathrm{L}$ tetracycline was added to avoid microbial contamination and the total volume of enzymatic hydrolysis was $50 \mathrm{~mL}$. The reaction was conducted at $50{ }^{\circ} \mathrm{C}$ using a thermostat shaker at $150 \mathrm{rpm}$ for slurry agitation in an environmental incubator shaker (New Brunswick Scientific, USA). After $72 \mathrm{~h}$ of hydrolysis, hydrolysate aliquots were withdrawn for further analysis. The obtained enzymatic hydrolysate was centrifuged at $10,000 \mathrm{rpm}$ for $10 \mathrm{~min}$ to remove suspended solids. Supernatant was then diluted in order to analyze monosaccharide concentrations by high-performance liquid chromatography (HPLC). The enzymatic digestibility of pretreated residue was calculated as the following equation:

$$
\begin{aligned}
& \text { Enzymatic digestibility }(\%) \\
& \qquad \begin{array}{l}
=\frac{\text { glucose in enzymatic hydrolysate }(\mathrm{g})}{\text { initial glucan in pretreated solid }(\mathrm{g}) \times 1.11} \\
\quad \times 100 \%
\end{array}
\end{aligned}
$$

\section{Direct red staining of pretreated WS for accessibility estimation}

The accessibility of pretreated residues was estimated by the direct red 28 (DR 28) staining assay according to literature [48]. For direct red adsorption, 1\% (w/v) washed substrate was loaded into $50 \mathrm{~mL}$ bottle and mixed with $20 \mathrm{~mL}$ distilled water in which direct red dye was dissolved. A series of increasing DR 28 concentrations (0, $0.05,0.1,0.5,1.0,2.0,3.0,4.0 \mathrm{~g} / \mathrm{L}$ ) was applied into each bottle and the bottles were incubated in a rotary shaker at $60{ }^{\circ} \mathrm{C}$ and $150 \mathrm{rpm}$ agitation for $24 \mathrm{~h}$. After incubation, $10 \mathrm{~mL}$ was withdrawn and centrifuged at $2500 \mathrm{rpm}$ 
for $5 \mathrm{~min}$ to remove suspended solids. Supernatant absorbance of samples was measured by UV-Vis spectrophotometry at $498 \mathrm{~nm}$. According to the absorbance readings, the amount of adsorbed dye was calculated as the difference between initial dye concentration and the dye concentration in the supernatant. Langmuir nonlinear regression was used to estimate the maximum adsorption capacity of direct red unto pretreated samples, which was interpreted as the enzymatic accessibility to pretreated residue.

\section{Chemical composition analysis of pretreated WS}

All experiments were carried out in duplicate and the means of duplicate analyses was reported in each figure and table. The infrared moisture meter (FD-720, KETT) was used to determine the moisture content of the pretreated materials. Chemical compositional analyses of all pretreated materials and prehydrolysates were carried out following the procedures of the NREL (National Renewable Energy Laboratory, Golden, Co, USA) standard analysis methods [49]. Determination of xylo-oligosaccharides was performed by $4 \mathrm{wt} \% \mathrm{H}_{2} \mathrm{SO}_{4}$ hydrolysis at $121{ }^{\circ} \mathrm{C}$ for $60 \mathrm{~min}$ according to the literature reported procedures [50]. Xylo-oligosaccharide concentrations were calculated from the increase in xylose concentration before and after acid hydrolysis. Analysis of monosaccharides and inhibitors was performed using HPLC (Agilent 1260 series, Agilent Technologies, Santa Clara, CA, USA). with an Aminex HPX-87H column and a refractive index (RI) detector. The column temperature was maintained at $55{ }^{\circ} \mathrm{C}$ and the mobile phase was $0.005 \mathrm{~mol} / \mathrm{L}$ $\mathrm{H}_{2} \mathrm{SO}_{4}$ at a flow rate of $0.6 \mathrm{~mL} / \mathrm{min}$.

\section{Abbreviations \\ EA: Exogenous ash; WS: Wheat straw; NREL: National Renewable Energy Laboratory; HPLC: High-performance liquid chromatography; HMF: Hydroxymethylfurfural.}

\section{Acknowledgements}

The research was supported by the National Natural Science Foundation of China (31870569) and the Doctorate Fellowship Foundation of Nanjing Forestry University. The authors also thank the financial support from the National First-class Disciplines (PNFD) and the Priority Academic Program Development (PAPD) of Jiangsu Higher Education Institutions.

\section{Authors' contributions}

XXW developed the idea for the study, performed the research, data analysis and prepared the manuscript. TW and $\mathrm{CH}$ helped to analyze the HPLC data. $\mathrm{CXH}$ helped to analyze the enzymatic digestibility and cellulose accessibility results. CHL and QY helped to revise the manuscript. All authors read and approved the final manuscript.

\section{Funding}

The research was supported by the National Natural Science Foundation of China (31870569).
Availability of data and materials

All data generated and analyzed in this study are included in this published article.

Ethics approval and consent to participate

Not applicable.

\section{Consent for publication}

Not applicable.

\section{Competing interests}

The authors declare that they have no competing interests.

\section{Author details}

${ }^{1}$ Key Laboratory of Forestry Genetics \& Biotechnology (Nanjing Forestry University), Ministry of Education, Nanjing 210037, People's Republic of China.

2 Jiangsu Co-Innovation Center of Efficient Processing and Utilization of Forest Resources, College of Chemical Engineering, Nanjing Forestry University, Nanjing 210037, People's Republic of China.

Received: 2 May 2020 Accepted: 6 July 2020

Published online: 13 July 2020

\section{References}

1. Ren N, Wang A, Cao G, Xu J, Gao L. Bioconversion of lignocellulosic biomass to hydrogen: potential and challenges. Biotechnol Adv. 2009:27:1051-60.

2. Nie S, Zhang C, Zhang Q, Zhang K, Zhang Y, Tao P, et al. Enzymatic and cold alkaline pretreatments of sugarcane bagasse pulp to produce cellulose nanofibrils using a mechanical method. Ind Crops Prod. 2018;124:435-41.

3. Lou Z, Yuan C, Zhang Y, Li Y, Cai J, Yang L, et al. Synthesis of porous carbon matrix with inlaid Fe3C/Fe3O4 micro-particles as an effective electromagnetic wave absorber from natural wood shavings. J Alloys Compd. 2019;775:800-9.

4. Wu Y, Wang S, Zhou D, Zhang Y, Wang X, Yang R. Biodegradable polyvinyl alcohol nanocomposites made from rice straw fibrils: mechanical and thermal properties. J Compos Mater. 2013:47:1449-59.

5. Du H, Liu W, Zhang M, Si C, Zhang X, Li B. Cellulose nanocrystals and cellulose nanofibrils based hydrogels for biomedical applications. Carbohydr Polym. 2019;209:130-44.

6. Tao P, Zhang Y, Wu Z, Liao X, Nie S. Enzymatic pretreatment for cellulose nanofibrils isolation from bagasse pulp: transition of cellulose crystal structure. Carbohydr Polym. 2019;214:1-7.

7. Huang C, Wang X, Liang C, Jiang X, Yang G, Xu J, et al. A sustainable process for procuring biologically active fractions of high-purity xylooligosaccharides and water-soluble lignin from Moso bamboo prehydrolyzate. Biotechnol Biofuels. 2019;12:189.

8. An L, Si C, Wang G, Sui W, Tao Z. Enhancing the solubility and antioxidant activity of high-molecular-weight lignin by moderate depolymerization via in situ ethanol/acid catalysis. Ind Crops Prod. 2019;128:177-85.

9. Alvira P, Tomás-Pejó E, Ballesteros M, Negro MJ. Pretreatment technologies for an efficient bioethanol production process based on enzymatic hydrolysis: a review. Bioresour Technol. 2010;101:4851-61.

10. Rabemanolontsoa H, Saka S. Various pretreatments of lignocellulosics. Bioresour Technol. 2016;199:83-91.

11. Shen XJ, Wen JL, Mei QQ, Chen X, Sun D, Yuan TQ, et al. Facile fractionation of lignocelluloses by biomass-derived deep eutectic solvent (DES) pretreatment for cellulose enzymatic hydrolysis and lignin valorization. Green Chem. 2019;21:275-83.

12. Huang $C$, Lin W, Lai C, Li X, Jin Y, Yong Q. Coupling the post-extraction process to remove residual lignin and alter the recalcitrant structures for improving the enzymatic digestibility of acid-pretreated bamboo residues. Bioresour Technol. 2019;285:121355.

13. Li X, Xu R, Yang J, Nie S, Liu D, Liu Y, et al. Production of 5-hydroxymethylfurfural and levulinic acid from lignocellulosic biomass and catalytic upgradation. Ind Crops Prod. 2019;130:184-97. 
14. Khalili F, Amiri H. Integrated processes for production of cellulosic and hemicellulosic biobutanol from sweet sorghum bagasse using autohydrolysis. Ind Crops Prod. 2020;145:111918.

15. Thompson VS, Lacey JA, Hartley D, Jindra MA, Aston JE, Thompson DN. Application of air classification and formulation to manage feedstock cost, quality and availability for bioenergy. Fuel. 2016;180:497-505.

16. Huang C, Wu X, Huang Y, Lai C, Li X, Yong Q. Prewashing enhances the liquid hot water pretreatment efficiency of waste wheat straw with high free ash content. Bioresour Technol. 2016;219:583-8.

17. Wu X, Huang C, Tang W, Huang C, Lai C, Yong Q. Use of metal chlorides during waste wheat straw autohydrolysis to overcome the self-buffering effect. Bioresour Technol. 2018;268:259-65.

18. Roy ED, Richards PD, Martinelli LA, Della CL, Lins SRM, Vazquez FF, et al. The phosphorus cost of agricultural intensification in the tropics. Nat Plants. 2016;2:16043.

19. Nicholson FA, Jones KC, Johnston AE. Effect of phosphate fertilizers and atmospheric deposition on long-term changes in the cadmium content of soils and crops. Environ Sci Technol. 1994;28:2170-5.

20. Barrow NJ. Soil phosphate chemistry and the P-sparing effect of previous phosphate applications. Plant Soil. 2015;397:401-9.

21. He Y, Fang Z, Zhang J, Li X, Bao J. De-ashing treatment of corn stover improves the efficiencies of enzymatic hydrolysis and consequent ethanol fermentation. Bioresour Technol. 2014;169:552-8.

22. Robert EP. Organic matter, humus, humate, humic acid, fulvic acid and humin: their importance in soil fertility and plant health. Igarss. 2014;2014:1-5.

23. Kelleher BP, Simpson AJ. Humic substances in soils: are they really chemically distinct? Environ Sci Technol. 2006;40:4605-11.

24. Christl I, Kretzschmar R. Relating ion binding by fulvic and humic acids to chemical composition and molecular size 1 Proton binding. Environ Sci Technol. 2001:35:2505-11.

25. Pertusatti J, Prado AGS. Buffer capacity of humic acid: thermodynamic approach. J Colloid Interface Sci. 2007;314:484-9.

26. Qing Q, Yang B, Wyman CE. Impact of surfactants on pretreatment of corn stover. Bioresour Technol. 2010;101:5941-51.

27. Zhuang X, Wang W, Yu Q, Qi W, Wang Q, Tan X, et al. Liquid hot water pretreatment of lignocellulosic biomass for bioethanol production accompanying with high valuable products. Bioresour Technol. 2016;199:68-75.

28. Wu X, Tang W, Huang C, Huang C, Lai C, Yong Q. The effects of exogenous ash on the autohydrolysis and enzymatic hydrolysis of wheat straw. Bioresour Technol. 2019;286:121411.

29. Chen X, Lawoko M, van Heiningen A. Kinetics and mechanism of autohydrolysis of hardwoods. Bioresour Technol. 2010;101:7812-9.

30. Narron $\mathrm{RH}, \mathrm{Han} \mathrm{Q}$, Park S, Chang H, Jameel H. Lignocentric analysis of a carbohydrate-producing lignocellulosic biorefinery process. Bioresour Technol. 2017:241:857-67.

31. Nabarlatz D, Farriol X, Montané D. Kinetic modeling of the autohydrolysis of lignocellulosic biomass for the production of hemicellulose-derived oligosaccharides. Ind Eng Chem Res. 2004:43:4124-31.

32. Tunc MS, Van Heiningen ARP. Hemicellulose extraction of mixed southern hardwood with water at $150^{\circ} \mathrm{C}$ : effect of time. Ind Eng Chem Res. 2008;47:7031-7.

33. Paces T. Activity coefficients in electrolyte solutions. Geochim Cosmochim Acta. 2003;69(12):3061-73.

34. Nitsos CK, Choli-Papadopoulou T, Matis KA, Triantafyllidis KS. Optimization of hydrothermal pretreatment of hardwood and softwood lignocellulosic residues for selective hemicellulose recovery and improved cellulose enzymatic hydrolysis. ACS Sustain Chem Eng. 2016;4:4529-44.
35. Salati S, Papa G, Adani F. Perspective on the use of humic acids from biomass as natural surfactants for industrial applications. Biotechnol Adv. 2011:29:913-22.

36. Savarino P, Montoneri E, Biasizzo M, Quagliotto P, Viscardi G, Boffa V. Upgrading biomass wastes in chemical technology Humic acid-like matter isolated from compost as chemical auxiliary for textile dyeing. J Chem Technol Biotechnol. 2007;82:939-48.

37. Poletto M, Ornaghi Júnior HL, Zattera AJ. Native cellulose: structure, characterization and thermal properties. Materials. 2014;7:6105-19.

38. Mosier N, Wyman C, Dale B, Elander R, Lee YY, Holtzapple M, et al. Features of promising technologies for pretreatment of lignocellulosic biomass. Bioresour Technol. 2005:96:673-86.

39. Hu J, Arantes V, Saddler JN. The enhancement of enzymatic hydrolysis of lignocellulosic substrates by the addition of accessory enzymes such as xylanase: is it an additive or synergistic effect? Biotechnol Biofuels. 2011;4:36.

40. Han X, Bao J. General method to correct the fluctuation of acid based pretreatment efficiency of lignocellulose for highly efficient bioconversion. ACS Sustain Chem Eng. 2018;6:4212-9.

41. Tang W, Wu X, Huang C, Huang C, Lai C, Yong Q. Enhancing enzymatic digestibility of waste wheat straw by presoaking to reduce the ashinfluencing effect on autohydrolysis. Biotechnol Biofuels. 2019;12:222.

42. Lee JM, Shi J, Venditti RA, Jameel H. Autohydrolysis pretreatment of Coastal Bermuda grass for increased enzyme hydrolysis. Bioresour Technol. 2009;100:6434-41.

43. Ishizawa Cl, Jeoh T, Adney WS, Himmel ME, Johnson DK, Davis MF. Can delignification decrease cellulose digestibility in acid pretreated corn stover? Cellulose. 2009;16:677-86.

44. Rahikainen JL, Martin-Sampedro R, Heikkinen H, Rovio S, Marjamaa K, Tamminen T, et al. Inhibitory effect of lignin during cellulose bioconversion: the effect of lignin chemistry on non-productive enzyme adsorption. Bioresour Technol. 2013;133:270-8.

45. Saini JK, Patel AK, Adsul M, Singhania RR. Cellulase adsorption on lignin: a roadblock for economic hydrolysis of biomass. Renew Energy. 2016:98:29-42

46. Wu J, Wu Y, Yang F, Tang C, Huang Q, Zhang J. Impact of delignification on morphological, optical and mechanical properties of transparent wood. Compos Part A Appl Sci Manuf. 2019;117:324-31.

47. Wiman M, Dienes D, Hansen MAT, Van Der Meulen T, Zacchi G, Lidén G. Cellulose accessibility determines the rate of enzymatic hydrolysis of steam-pretreated spruce. Bioresour Technol. 2012;126:208-15.

48. Inglesby MK, Zeronian SH. Direct dyes as molecular sensors to characterize cellulose substrates. Cellulose. 2002;9:19-29.

49. Sluiter A, Hames B, Ruiz R, Scarlata C, Sluiter J, Templeton D. Determination of ash in biomass: Laboratory Analytical Procedure (LAP). Nrel/ Tp-510-42622. 2008;18.

50. Xiao X, Bian J, Peng XP, Xu H, Xiao B, Sun RC. Autohydrolysis of bamboo (Dendrocalamus giganteus Munro) culm for the production of xylooligosaccharides. Bioresour Technol. 2013;138:63-70.

\section{Publisher's Note}

Springer Nature remains neutral with regard to jurisdictional claims in published maps and institutional affiliations.

Ready to submit your research? Choose BMC and benefit from:

- fast, convenient online submission

- thorough peer review by experienced researchers in your field

- rapid publication on acceptance

- support for research data, including large and complex data types

- gold Open Access which fosters wider collaboration and increased citations

- maximum visibility for your research: over 100M website views per year

At BMC, research is always in progress.

Learn more biomedcentral.com/submissions 